\title{
Factors affecting stillbirth: prospective study
}

\section{Balaji Jadhav ${ }^{1}$, Shweta Avinash Khade ${ }^{2 *}$, Ganesh Shinde ${ }^{3}$, Shilpa Chandan ${ }^{2}$}

\author{
${ }^{1}$ Department of Obstetrics and Gynecology, R. N. Cooper Hospital and HBT Medical College, Mumbai, Maharashtra, \\ India \\ ${ }^{2}$ Department of Obstetrics and Gynecology, Lokmanya Tilak Municipal General Hospital and Medical College, Sion, \\ Maharashtra, India \\ ${ }^{3}$ Department of Obstetrics and Gynecology, TNMC Nair Hospital, Mumbai central, Maharashtra, India
}

\author{
Received: 20 September 2020 \\ Revised: 07 February 2021 \\ Accepted: 09 February 2021
}

\author{
*Correspondence: \\ Dr. Shweta Avinash Khade, \\ E-mail: drshwetam2009@gmail.com
}

Copyright: () the author(s), publisher and licensee Medip Academy. This is an open-access article distributed under the terms of the Creative Commons Attribution Non-Commercial License, which permits unrestricted non-commercial use, distribution, and reproduction in any medium, provided the original work is properly cited.

\begin{abstract}
Background: Stillbirth is defined by WHO as the birth of a baby with a birth weight of 500 gm or more, 22 or more completed weeks of gestation or a body length of $25 \mathrm{~cm}$ or more, who died before or during labour and birth.

Methods: This was prospective observational study of factors affecting stillbirth was conducted in tertiary hospital for a period of 1 year from $1^{\text {st }}$ June 2014 to $31^{\text {st }}$ May 2015. During the study period, 200 parturient of gestational age 28 weeks or more and fetal weight 1000 gm or more with or without medical disorders were included.

Results: The total number of births during study period was 11,951. Stillbirth rate in the present study was 16.73 per 1000 births. Most of stillbirths were seen in the antepartum period $(76 \%)$ when compared to intrapartum period (24\%). Maximum stillbirths occurred in gestational age of 36 weeks and above (52\%) and fetal weight between 20012500 gm (27.50\%). Patients with inadequate antenatal care, less than three visits had $86 \%$ stillbirths.

Conclusions: Proper antenatal care, prompt referral services and availability of emergency obstetric care will provide a pivotal role for reduction of stillbirths.
\end{abstract}

Keywords: Antepartum, Delivery, Intrapartum, Fetal weight, Gestational age, Stillbirth

\section{INTRODUCTION}

Stillbirth is defined by WHO as the birth of a baby with a birth weight of $500 \mathrm{gm}$ or more, 22 or more completed weeks of gestation or a body length of $25 \mathrm{~cm}$ or more, who died before or during labour and birth. ${ }^{1}$ For international comparisons, WHO recommends reporting of stillbirths with birth weight of $1000 \mathrm{gm}$ or more, 28 weeks of gestation or more or a body length of $35 \mathrm{~cm}$ or more. The gestation threshold of 28 weeks or longer has public health relevance. In countries in which $98 \%$ of neonatal deaths occurs, neonatal intensive care is not widely available and few births before 28 weeks of gestation survive.

The International Classification of Diseases, $10^{\text {th }}$ revision (ICD-10) refers to fetal deaths not stillbirths. "Death prior to the complete expulsion or extraction from its mother of a product of human conception, the fetus does not breathe or show any other evidence of life, such as beating of the heart, pulsation of the umbilical cord, or definitive movement of voluntary muscles". In ICD-10, the measurement of focus is on fetal deaths in last trimester of pregnancy and is defined by a birth weight of $500 \mathrm{gm}$ or more; if birth weight not known, by gestational age of 22 weeks or more; or if both these criteria not known, by crown heel length of $25 \mathrm{~cm}$ or more.

New estimates of stillbirth trends from 1995 to 2009 suggest that the average worldwide yearly rate of reduction has reduced by $1.1 \%$ which is lower than the reduction for mortality in children younger than 5 years and is less than that for maternal mortality reduction (1.3\%). ${ }^{1}$ Comparing 1995 to 2009 stillbirth rates, the 
smallest declines were reported in Sub-Saharan Africa and Oceania. Significant declines were reported in China, Bangladesh and India which had a combined estimate of 4,00,000 fewer stillbirths in 2009 than in 1995.

Still birth rate is defined as death of a fetus weighing $1000 \mathrm{~g}$ (this is equivalent to 28 weeks of gestation) or more occurring during one year in every 1000 total births (live births plus stillbirths). ${ }^{2}$

The five major causes of stillbirths are childbirth complications, maternal infections, maternal disorders, especially hypertension, maternal malnutrition, fetal growth restriction and congenital abnormalities. In high income countries, infections associated with preterm birth, diabetes and post-term pregnancy are additional important causes, as many of the other major preventable causes of stillbirth have reduced rates or have been eliminated. Contributing to the risk in high-income countries are high or increasing levels of maternal smoking, obesity and advanced maternal age. Stillbirth rates have been proposed as a sensitive marker of inequity and are closely linked to social deprivation, poor maternal health and service availability and quality.

Stillbirth prevention is closely linked to prevention of maternal and neonatal deaths. Ignoring stillbirths is a missed opportunity to measure effect of programs for maternal, neonatal and fetal health. Knowledge of causes and feasible solutions of stillbirths for prevention is key to health professional's priorities. Improvements in the quality of and access to key-life saving interventions, through the facilitating of access to transportation to medical facilities, training of health-care personnel, including obstetric drills and audits, and the use of maternity waiting homes where high risk women can await birth near medical facilities, are likely to prevent multiple obstetric disorders, augment treatment and lower rates of adverse outcome. This present study was undertaken to study various factors affecting still births related to obstetric events and to find out preventable factors for still births.

\section{Aims and objectives}

To know various factors affecting still births related to obstetric events; to understand the trend of stillbirths and to identify preventable factors of still births.

\section{METHODS}

The present prospective study was conducted in the medical college and hospital in one of the metro cities of Maharashtra state with a study period of 1 year.

\section{Sample size}

200 cases (All cases admitted in labour room with gestational age above 28 weeks during one year from $1^{\text {st }}$ June 2014 to $31^{\text {st }}$ May 2015 study period).

\section{Inclusion criteria}

Gestational age more than 28 weeks. Birth weight more than $1000 \mathrm{gm}$. Medical disorders.

\section{Exclusion criteria}

Gestational age less than 28 weeks. Birth weight less than $1000 \mathrm{gm}$. Congenital anomalies outside delivery.

\section{Data collection tools}

Case record proforma designed to study factors affecting stillbirth. History regarding age, parity, gestational age, socioeconomic status, patient's education and patient's husband's education, reason for referral, whether onset of labour was spontaneous or induced, method of induction of labour, indication for induction of labour, duration of labour, mode of delivery, interval between admission and time of delivery, stage of labour at which still birth occurred, past history of still birth, associated medical disorders, birth weight of baby and gender of baby was recorded.

\section{Statistical methods}

Data analysis by frequency tables, bivariate analysis, significant level $\mathrm{p}<0.5$, confidence interval at $95 \%$, Chi square test and t test applied whenever necessary. Data analysis done by software using SPSS, IBM software version 16 .

\section{RESULTS}

Table 1 shows gestational age among study group. In this study, $52.5 \%$ were in gestational age of 36 weeks and above. $27.5 \%$ patients were in gestational age of 32 to 35 weeks. $20.5 \%$ patients were in gestational age of 28 to 31 weeks.

Table 1: Gestational age among study group.

\begin{tabular}{|lll|}
\hline Gestational age (weeks) & Frequency & Percentage \\
\hline $\mathbf{2 8}$ to 31 & 41 & 20.5 \\
\hline $\mathbf{3 2}$ to 35 & 55 & 27.5 \\
\hline 36 and above & 104 & 52 \\
\hline Total & 200 & 100 \\
\hline
\end{tabular}

Table 2: Birth weight of baby.

\begin{tabular}{|lll|}
\hline Birth weight $(\mathrm{gm})$ & Frequency & Percentage \\
\hline $\mathbf{1 0 0 0}$ to $\mathbf{1 5 0 0}$ & 40 & 20.00 \\
\hline $\mathbf{1 5 0 1}$ to 2000 & 50 & 25.00 \\
\hline $\mathbf{2 0 0 1}$ to 2500 & 55 & 27.50 \\
\hline $\mathbf{2 5 0 1}$ to 3000 & 32 & 16.00 \\
\hline Above 3000 & 23 & 11.50 \\
\hline Total & 200 & 100 \\
\hline
\end{tabular}


Table 2 shows birth weight of baby. In this study, maximum (27.50\%) babies were weighing between 2001 to $2500 \mathrm{gms}$. $25 \%$ were weighing between 1501 to 2000gms, 20\% weighed between 1000 to $1500 \mathrm{gm}, 16 \%$ weighed between 2501 to $3000 \mathrm{gm}, 11.50 \%$ above 3000 gm.

Table 3: Reason for referral.

\begin{tabular}{|lll|}
\hline Reason for referral & Frequency & Percentage \\
\hline IUFD & 48 & 36.36 \\
\hline Abruptio placentae & 18 & 13.63 \\
\hline Labour complications & 16 & 12.1 \\
\hline Hypertensive disorders & 12 & 9.08 \\
\hline Oligohydramnios & 6 & 4.5 \\
\hline Postdatism & 7 & 5.3 \\
\hline Decreased fetal movements & 7 & 5.3 \\
\hline Medical disorders & 8 & 6.06 \\
\hline Non availability of facility & 10 & 7.57 \\
\hline
\end{tabular}

Table 3 shows reason for referral. In this study, $36.36 \%$ cases were referred as IUFD. Abruptio placentae (13.63\%), labour complications $(12.1 \%)$, hypertensive disorders $(9.08 \%)$, oligohydramnios $(4.5 \%)$, postdatism $(5.3 \%)$, decreased fetal movements $(5.35 \%)$, medical disorders $(6.06 \%)$, non-availability of facility $(7.57 \%)$ were other reasons for referral.

Table 4: Obstetrical complications.

\begin{tabular}{|l|ll|}
\hline Obstetric complications & Frequency & Percentage \\
\hline Abruptio placentae & 26 & 13 \\
\hline Oligohydramnios & 23 & 11.5 \\
\hline Labour complications & 17 & 8.5 \\
\hline Hypertensive disorders & 16 & 8.00 \\
\hline Poor monitoring & 10 & 5.00 \\
\hline Undetermined & 108 & 54 \\
\hline Total & 200 & 100 \\
\hline
\end{tabular}

Table 4 shows obstetrical complications: abruptio placentae accounted for maximum cases (13\%). Other were oligohydramnios $(11.5 \%)$, labour complications $(8.5 \%)$, hypertensive disorders $(8 \%)$, poor monitoring $(5 \%)$. Cause of death was undetermined in $54 \%$ of cases.

Table 5: Medical disorders.

\begin{tabular}{|lll|}
\hline Medical disorders & Frequency & Percentage \\
\hline Hypothyroidism & 7 & 3.5 \\
\hline Diabetes mellitus & 6 & 3 \\
\hline Hepatitis E & 5 & 2.5 \\
\hline Chronic kidney disease & 5 & 2.5 \\
\hline No medical disease & 177 & 88.50 \\
\hline Total & 200 & 100 \\
\hline
\end{tabular}

Table 5 shows medical disorders. In this study, $11.5 \%$ patients had medical disorders, $88.50 \%$ patients had no medical disorders associated. Hypothyroidism was the commonest medical disease $(3.5 \%)$ followed by diabetes mellitus (3\%).

Figure 1 presents data regarding mode of delivery. $(79.50 \%)$ were delivered vaginally and $20.50 \%$ percent underwent LSCS.

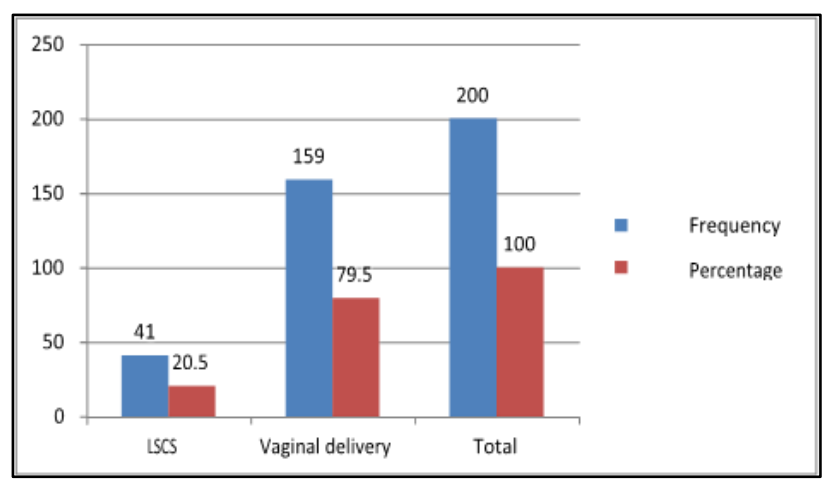

Figure 1: Mode of delivery.

Table 6: Antepartum/intrapartum stillbirths by age of patients.

\begin{tabular}{|c|c|c|c|}
\hline Age (years) & Antepartum & Intrapartum & Total \\
\hline 20 to 25 & $85(55.9 \%)$ & $20(41.7 \%)$ & $105(52.5 \%)$ \\
\hline 26 to 30 & $45(29.6 \%)$ & $15(31.3 \%)$ & $60(30 \%)$ \\
\hline Above 30 & $22(14.5 \%)$ & $13(27 \%)$ & $35(17.5 \%)$ \\
\hline Total & $152(100 \%)$ & $48(100 \%)$ & $200(100 \%)$ \\
\hline Chi-square & Df & $P$ value & $\begin{array}{l}\text { Association } \\
\text { is }\end{array}$ \\
\hline $\begin{array}{l}\text { Pearson } \\
\text { Chi-square }\end{array}$ & 2 & 0.093 & $\begin{array}{l}\text { Not } \\
\text { significant }\end{array}$ \\
\hline
\end{tabular}

Table 6 shows antepartum/intrapartum stillbirths by age of patients. $55.9 \%$ antepartum stillbirths and $41.70 \%$ intrapartum stillbirths were in 20 to 25 years age group. In age group of 26 to 30 years, there were $29.60 \%$ antepartum stillbirths and $31.30 \%$ intrapartum stillbirths. In above 30 years age group, there were $14.5 \%$ antepartum stillbirths and $27.10 \%$ intrapartum stillbirths. More antepartum and intrapartum stillbirths were seen in age group of 20 to 25 years, but there is no direct correlation between age group and antepartum/ intrapartum stillbirths.

Table 7 shows antepartum/intrapartum stillbirths by gestational age. In this study, $24.3 \%$ antepartum stillbirths and $8.3 \%$ intrapartum stillbirths were in gestational age of 28 to 31 weeks. In gestational age of 32 to 35 weeks, $33.2 \%$ antepartum stillbirths and $12.5 \%$ intrapartum stillbirths were observed. In gestational age of 36 weeks and above, $44.42 \%$ antepartum stillbirths and $79.16 \%$ intrapartum stillbirths were observed. Maximum antepartum and intrapartum stillbirths were seen in gestational age of 36 weeks and above. Direct correlation observed between antepartum/intrapartum stillbirths and gestational age. 
Table 7: Antepartum/intrapartum stillbirths by gestational age.

\begin{tabular}{|llll|}
\hline Gestational age (weeks) & Antepartum & Intrapartum & Total \\
\hline $\mathbf{2 8}$ to 31 & $37(24.30 \%)$ & $4(8.3 \%)$ & $41(20.5 \%)$ \\
\hline $\mathbf{3 2}$ to 35 & $49(33.2 \%)$ & $6(12.5 \%)$ & $55(27.5 \%)$ \\
\hline $\mathbf{3 6}$ and above & $66(44.42 \%)$ & $38(79.16 \%)$ & $104(52 \%)$ \\
\hline Total & $152(100 \%)$ & $48(100 \%)$ & $200(100 \%)$ \\
\hline Chi-square test & Df & P value & Association is \\
\hline Pearson Chi-square & 3 & $<0.0001$ & Significant \\
\hline
\end{tabular}

Table 8: Antepartum/intrapartum stillbirths by referral.

\begin{tabular}{|llll|}
\hline Referred case & Antepartum & Intrapartum & Total \\
\hline Yes & $94(61.8 \%)$ & $38(79.2 \%)$ & $132(66 \%)$ \\
\hline No & $58(38.20 \%)$ & $10(20.80 \%)$ & $68(34 \%)$ \\
\hline Total & $152(100 \%)$ & $48(100 \%)$ & $200(100 \%)$ \\
\hline Chi-square test & Df & P value & Association is \\
\hline Pearson Chi-square & 1 & 0.027 & Significant \\
\hline Fisher's exact test & & 0.035 & Significant \\
\hline
\end{tabular}

Table 9: Antepartum/intrapartum stillbirths by mode of delivery.

\begin{tabular}{|llll|}
\hline Mode of delivery & Antepartum & Intrapartum & Total \\
\hline LSCS & $18(11.8 \%)$ & $23(47.9 \%)$ & $41(20.5 \%)$ \\
\hline Vaginal delivery & $134(88.20 \%)$ & $25(52.1 \%)$ & $159(79.5 \%)$ \\
\hline Total & $152(100 \%)$ & $48(100 \%)$ & $200(100 \%)$ \\
\hline Chi-square test & Df & P value & Association is \\
\hline Pearson Chi-square test & 1 & $<0.001$ & Significant \\
\hline Fisher's exact test & & $<0.001$ & Significant \\
\hline
\end{tabular}

Table 10: Antepartum/intrapartum stillbirths by birth weight.

\begin{tabular}{|llll|}
\hline Birth weight $(\mathrm{gm})$ & Antepartum & Intrapartum & Total \\
\hline $\mathbf{1 0 0 0 - 1 5 0 0}$ & $37(24.3 \%)$ & $3(6.3 \%)$ & $40(20 \%)$ \\
\hline $\mathbf{1 5 0 1 - 2 0 0 0}$ & $42(27.6 \%)$ & $8(16.7 \%)$ & $50(25 \%)$ \\
\hline $\mathbf{2 0 0 1 - 2 5 0 0}$ & $35(23 \%)$ & $20(41.7 \%)$ & $55(27.5 \%)$ \\
\hline $\mathbf{2 5 0 1 - 3 0 0 0}$ & $22(14.5 \%)$ & $10(20.8 \%)$ & $32(16 \%)$ \\
\hline Above 3000 & $16(10.5 \%)$ & $7(14.6 \%)$ & $23(11.5 \%)$ \\
\hline Total & $152(100 \%)$ & $48(100 \%)$ & $200(100 \%)$ \\
\hline Chi-square test & Df & P value & Association is \\
\hline Pearson Chi-square & 4 & 0.008 & Significant \\
\hline
\end{tabular}

Table 8 shows antepartum/intrapartum stillbirths by referral. In this study, $61.80 \%$ antepartum stillbirths and $79.20 \%$ intrapartum stillbirths were observed in referred cases. In cases without referral, $38.20 \%$ antepartum stillbirths and $20.80 \%$ intrapartum stillbirths were observed. More intrapartum stillbirths were seen in referred cases compared to antepartum stillbirths. There was direct correlation between antepartum and intrapartum stillbirths and referral.

Table 9 presents data on antepartum/intrapartum stillbirths by mode of delivery. In vaginal delivery, $88.20 \%$ antepartum stillbirths and $52.10 \%$ intrapartum stillbirths were observed. Patients who underwent LSCS had $47.90 \%$ intrapartum stillbirths and $11.80 \%$ antepartum stillbirths. More antepartum and intrapartum stillbirths were seen in patients who delivered vaginally. Direct correlation was found between antepartum and intrapartum stillbirths and mode of delivery.

Table 10 presents data on antepartum/intrapartum stillbirths by birth weight. In this study, $24.3 \%$ antepartum stillbirths and $6.30 \%$ intrapartum stillbirths were in babies with birth weight between 1000 to 1500 gm. In birth weight range of 1501 to 2000 gm there were $27.60 \%$ antepartum stillbirths and $16.70 \%$ intrapartum 
stillbirths. In birth weight range of 2001 to 2500 gm, $23 \%$ antepartum stillbirths and $41.75 \%$ intrapartum stillbirths were observed. In birth weight range of 2501 to $3000 \mathrm{gm}$, $14.5 \%$ antepartum stillbirths and $20.80 \%$ intrapartum stillbirths were observed. There were $10.50 \%$ antepartum stillbirths and $14.6 \%$ intrapartum stillbirths in babies with birth weight above 3000 gm. More antepartum stillbirths (27.6\%), were seen in birth weight range of 1501 to 2000 gm. More intrapartum stillbirths $(41.70 \%)$ were in birth weight range of 2001 to $2500 \mathrm{gm}$. Direct correlation observed between antepartum/intrapartum stillbirths and birth weight.

Table 11: Distribution of referral cases by gestational age group.

\begin{tabular}{|llll|}
\hline Gestational age (weeks) & Referred case & No & Total \\
\hline 28 to 31 & Yes & $15(22.05 \%)$ & $41(20.5 \%)$ \\
\hline $\mathbf{3 2}$ to 35 & $26(19.69 \%)$ & $23(33.82 \%)$ & $55(27.5 \%)$ \\
\hline 36 and above & $32(24.4 \%)$ & $30(44.11 \%)$ & $104(52 \%)$ \\
\hline Total & $74(56.06 \%)$ & $68(34 \%)$ & $200(100 \%)$ \\
\hline Chi-square & $132(100 \%)$ & P value & Association is \\
\hline Pearson Chi-square & Df & 0.2404 & Not significant \\
\hline
\end{tabular}

Table 11 presents data of gestational age by referred cases. In this study, maximum referred patients $(56.06 \%)$ had gestational age of 36 weeks and above. There were $24.4 \%$ referral cases in gestational age between 32 to 35 weeks. There were $19.69 \%$ referred cases in gestational age between 28 to 31 weeks. No direct correlation observed between gestational age and referred cases

\section{DISCUSSION}

This study was a prospective observational study for determining factors affecting stillbirths conducted in medical college over a period of one year after obtaining proper consent from patients and ethical committee clearance. During the study period, 200 parturient fulfilled the inclusion criteria and were included in the study. The results obtained were compared with literature and other studies. The total number of births during study period was 11,951 . Stillbirth rate in the present study was 16.73 per 1000 births.

\section{Age group}

In the age group of 20 to 25 years, there were $52 \%$ patients, in our study $52.5 \%$ stillbirths were observed in the $20-25$ years age group.

\section{Socio-economic status}

Maximum number of stillbirths (54\%) observed in patients with below poverty line socio economic status.

\section{Gravida}

In this study, maximum $(55 \%)$ patients were primigravida. $45 \%$ were multigravida. Gravidity also matters the stillbirth rate. $55 \%$ stillbirths in multigravida in our study.

\section{Gestational age}

In this study, stillbirths were higher (52\%) at the gestational age of 36 weeks and above while it was $48 \%$ stillbirths in gestational age less than 36 weeks.

\section{Antepartum or intrapartum stillbirth}

In this study, maximum stillbirths $(76 \%)$ were in antepartum period compared to 24 percent in intrapartum period compared to 78 antepartum and 22 intrapartum in Rayamajhi et al study, $61 \%$ antepartum and $39 \%$ intrapartum stillbirths in Vidyadhar study. ${ }^{3,4}$ Prasanna et al study observed $72.82 \%$ antepartum stillbirths and $21.18 \%$ intrapartum stillbirths. ${ }^{5}$

In our study antepartum stillbirths in gestational age of $36-40$ weeks was $42.8 \%$ compared to $42 \%$ in Shaaban et al study. ${ }^{6}$ Stillbirth rate was higher at the gestational age of 36 weeks and above, it means when baby was near term and term.

In this study, $55.9 \%$ antepartum stillbirths and $41.70 \%$ intrapartum stillbirths were in 20 to 25 years age group.

\section{Stillbirth by birth weight}

In this study maximum number of stillbirths were with birth weight of $2001-2500 \mathrm{gm}(27.5 \%)$ and $72.5 \%$ of low-birth-weight babies. This finding was similar to Rayamajhi et al study, with $27.8 \%$ stillbirths observed in birth weight range of 2000 to $2500 \mathrm{gm}$ and overall low birth weight babies accounted for $66.6 \% .^{3}$ According to Vidhyadar et al study, low birth weight and prematurity 
were responsible for $80 \%$ of stillbirths. ${ }^{4}$ Birth weight of stillbirth may not be accurate and may be influenced by number of days since fetal death.

It means, stillbirth with this birth weights were salvageable even at screwed resources facility. Weak referral facilities were associated with high stillbirth rate in Bhattacharya et al study, Ntuli et al study and Rehman et al study. ${ }^{7-9}$ In the present study, among $66 \%$ referred patients, 36.6\% already had intrauterine fetal death and $13.63 \%$ had abruption placentae.

\section{Obstetric complications}

The present study had $13 \%$ stillbirths due to abruption placentae, most common reason for stillbirths. Abruption placentae was responsible for $12 \%$ of stillbirths in Vidhyadar et al study and $15 \%$ in Gardosi et al study. ${ }^{4,10}$

\section{Medical disorders}

Medical disorders during pregnancy accounts for $11.5 \%$ stillbirth rate in our study compared to $5 \%$ in Vidhyadar study, $7.1 \%$ in Rawat et al study and $8 \%$ in Bhattacharya et al study. ${ }^{4,7,11}$ No significant difference observed with other studies.

\section{Mode of delivery}

In this study, vaginal delivery $(79.5 \%)$ was most common mode of delivery. $20.5 \%$ delivered by LSCS compared to $73.1 \%$ vaginal delivery in Nayak et al study and $70 \%$ vaginal delivery in Ntuli study. 8,12

In vaginal delivery, $88.20 \%$ antepartum stillbirths and $52.10 \%$ intrapartum stillbirths were observed. Patients who underwent LSCS had $47.90 \%$ intrapartum stillbirths and $11.80 \%$ antepartum stillbirths. More antepartum and intrapartum stillbirths were seen in patients who delivered vaginally. Direct correlation was found between antepartum and intrapartum stillbirths and mode of delivery.

\section{Antenatal visits}

In this study, $86 \%$ patients had less than 3 ANC visits. $14 \%$ were unregistered and $14 \%$ had more than 3 ANC visits.

In $54 \%$ of cases, cause of death was undetermined. This seems to be mentally traumatic to the patient. Hence whenever we get the opportunity and patients are found stable, detailed interview with patient, her previous records and quality of antenatal care should be noted.

The biggest concern to quality of ANC care is that does the patient understand for what she has come? The Health delivery system only addresses the number of ANC visits which means minimum three are enough.
The present study and other studies were hospital based. They may represent gist of the problem and not true magnitude of it. ANC visits by public health workers at doorstep may give some insight into the still unforeseen stillbirth rate. Therefore, we must find the preventable factors, seasonal infections and other social issues of women during her pregnancy. The more we understand preventable factors, maximum efforts can be diverted to them.

In this study, $6.25 \%$ antepartum stillbirths and $8.92 \%$ intrapartum stillbirths were seen in unregistered patients. In patients with upto 3 ANC visits, $88.88 \%$ antepartum stillbirths and $78.57 \%$ intrapartum stillbirths were observed. In patients with more than 3 ANC visits, $4.8 \%$ antepartum and $12.5 \%$ intrapartum stillbirths were observed. Maximum antepartum and intrapartum stillbirths were observed in patients with upto 3 ANC visits. But no direct correlation found between Antepartum/intrapartum stillbirths and ANC visits.

\section{Referral}

In this study, $66 \%$ cases were referred and $34 \%$ were self-referral. In this study, $36.36 \%$ cases were referred as IUFD. Abruptio placentae (13.63\%), labour complications $(12.1 \%)$, hypertensive disorders $(9.08 \%)$, oligohydramnios $(4.5 \%)$, postdatism $(5.3 \%)$, decreased fetal movements $(5.35 \%)$, medical disorders $(6.06 \%)$, non-availability of facility $(7.57 \%)$ were other reasons for referral.

In this study, $61.80 \%$ antepartum stillbirths and $79.20 \%$ intrapartum stillbirths were observed in referred cases. In cases without referral, $38.20 \%$ antepartum stillbirths and $20.80 \%$ intrapartum stillbirths were observed. More intrapartum stillbirths were seen in referred cases compared to antepartum stillbirths. There is direct correlation between antepartum/intrapartum stillbirths and referral.

\section{CONCLUSION}

A significant proportion of stillbirths are preventable by adequate antenatal care. Behind the preventable causes, the main cause of stillbirth is the suboptimal antenatal and intrapartum care. Female literacy and health education will increase the awareness about antenatal care. Ignorance, poverty, illiteracy and poor support from family especially the husband, also contribute to inadequate antenatal care. The causes for suboptimal care are divided at primary health center level and tertiary health care level. Primary health care providers contributed to suboptimal care by failure to recognize high-risk cases, leading to late referrals. Areas of suboptimal care at tertiary health care level included failure to manage high risk cases, delay/error in labour management, and poor counselling. 
The importance of adequate antenatal care, identification of high-risk cases, and timely referral needs to be emphasized among the medical and paramedical personnel at the first point of contact with the pregnant women. Prompt care by well-equipped tertiary centers and periodic departmental audits will help achieve the goal of reducing stillbirths. Proper antenatal care, prompt referral services and availability of emergency obstetric care will provide a pivotal role for reduction of stillbirths.

Funding: No funding sources

Conflict of interest: None declared

Ethical approval: The study was approved by the Institutional Ethics Committee

\section{REFERENCES}

1. Lawn JE, Blencowe H, Pattinson R, Cousens S, Kumar R, Ibiebele I, et al. Stillbirths: Where? When? Why? How to make the data count? Lancet. 2011;377(9775):1448-63

2. K Park K. Textbook of Preventive and Social Medicine. 22nd edn. M/s Banarsidas Bhanot Publishers; 2013:521.

3. Rayamajhi RT, Shreshtha N, Karki C. Evaluation of clinicosocial factors associated with antepartum and intrapartum stillbirths at Kathmandu Medical College Teaching Hospital. South Asian Feder Obstet Gynecol. 2009;1(1):14-8.

4. Vidyadhar BB, Rajiv CM, Pandit H. A Review of socio demographic factors and obstetric causes of stillbirths at tertiary care hospital, IOSR J Pharm. 2012;2(3):475-8.
5. Prasanna N, Ramalingappa KM. Cause of death and associated conditions of stillbirths. Int $\mathrm{J}$ Reprod Contracept Obstet Gynecol. 2015;4(6):1970-4.

6. Shaaban LA, Al-Saleh RA, Alwafi BM, Al-Raddadi RM. Associated risk factors with ante-partum intrauterine fetal death. Saudi Med J. 2006J;27(1):76-9.

7. Bhattacharyya R, Pal A. Stillbirths in a referral medical college hospital, West Bengal, India: a tenyear review. J Obstet Gynaecol Res. 2011;38(1):26671.

8. Ntuli ST, Malangu N. An investigation of the stillbirths at a tertiary hospital in Limpopo province of South Africa. Glob J Health Sci. 2012;4(6):141.

9. Rahaman H, Dutta S, Kar S. Determinants of stillbirths in a teaching hospital of Sikkim Province of India, J Womens Health Issues Care. 2014;3(5):15 .

10. Gardosi J, Mu T, Mongelli M. Analysis of birthweight and gestational age in anteparturn stillbirths. Br J Obstet Gynaecol. 1998;105: 524-30.

11. Rawat R, Toppo M, Pal DK. Stillbirths in a tertiary care hospital. Bhopal J Evol Med Dent Sci. 2015;4(05):767-72.

12. Korde-Nayak Vaishali N, Gaikwad Pradeep R. Causes of stillbirth. $\mathrm{J}$ Obstet Gynecol India. 2008;58(4):314-8.

Cite this article as: Jadhav B, Khade SA, Shinde G, Chandan S. Factors affecting stillbirth: prospective study. Int J Reprod Contracept Obstet Gynecol 2021;10:939-45. 